\title{
Publication Information:
}

Pearce, MJ, Pargament, KI, Oxhandler, H., Vieten, C., \& Wong, S. (2019). A novel training program for mental health providers in spiritual competencies. Spirituality in Clinical Practice. Online first DOI: 10.1037/scp0000195

A Novel Training Program for Mental Health Providers in

Religious and Spiritual Competencies

Michelle J. Pearce, PhD*

Graduate School, University of Maryland, Baltimore, MD

Department of Psychiatry and Behavioral Sciences, Duke University Medical Center, Durham, NC

Kenneth I. Pargament, PhD

Bowling Green State University, Bowling Green, $\mathrm{OH}$

Holly K. Oxhandler, PhD, LMSW

Baylor University, Waco, TX

Cassandra Vieten, PhD

Institute of Noetic Sciences, Petaluma, CA

Serena Wong, MA

Bowling Green State University, Bowling Green, $\mathrm{OH}$

Word count: 3,380 (text only) 
*Corresponding Author: Michelle Pearce, PhD, 620 W. Lexington St., Rm 1115, Graduate

School, University of Maryland, Baltimore, Baltimore, MD, 21021. E-mail:

michelle.pearce@umaryland.edu. Phone 410-706-6164.

Funding support provided by the John Templeton Foundation, Grant 60791

\begin{abstract}
Religion and spirituality are areas of diversity and multiculturalism that have yet to be comprehensively addressed in most mental health training programs. Without this type of training, many practitioners lack the competence and confidence to engage in spiritually competent care-clinical practice that recognizes the importance of religion and spirituality in people's identity, worldview, meaning-making and, therefore, their psychological well-being. Emerging research on treatment outcomes and client preferences, as well as professional ethical mandates, support the need for training in spiritual competencies for mental health care. To address the gap between current professional training and the needs and realities of clinical practice, we have developed an online training program to assist practitioners in building their competency and comfort levels in integrating religion and spirituality into treatment. Spiritual Competency Training in Mental Health (SCT-MH) is a seven hour asynchronous, online program consisting of eight modules. The modules are designed to develop basic competency in 16 empirically-derived spiritual competencies in mental health. The content was derived from numerous instructional materials and peer-reviewed publications, with input from leading experts in the field of spirituality and mental health. It is a
\end{abstract}


multidisciplinary program, allowing mental health providers from any discipline and orientation to participate. The material is applicable for working with clients with a wide range of mental health issues from diverse religious and spiritual backgrounds. In this manuscript, we will discuss how the program was developed, what it entails, who it was developed for, and future efforts to test it empirically.

5 Keywords or Phrases: Spirituality, Religion, Mental Health, Therapy, Training

Acknowledgements: We would like to offer a special thank you to our instructional design team at the University of Maryland, Baltimore for their creative ideas and hard work translating the program content into engaging edX material. 


\section{A Novel Training Program for Mental Health Providers in \\ Religious and Spiritual Competencies}

The goal of professional mental health training across helping professions is to develop competence in the delivery of effective and ethical clinical care. Graduate training programs for mental health care providers are expected to establish a certain level of competence upon graduation (American Psychological Association [APA], 2015; Commission on Accreditation for Marriage and Family Therapy Education [COAMFTE] , 2016; Council for Accreditation of Counseling and Related Educational Programs [CACREP], 2016; Council on Social Work Education [CSWE], 2015). One area of shared clinical competence is multiculturalism. As we learn more about various layers of ethnic, cultural, regional, age, gender, and religious/spiritual diversity and intersectionality, their impact on clinical care and outcomes, and potential biases related to these areas of diversity, it is important that our training programs evolve to better prepare us to be multiculturally competent practitioners. Without this type of training, many mental health practitioners lack the ability to engage in spiritually competent care and engage in it less frequently (Oxhandler, Parrish, Torres, \& Achenbaum, 2015; Rosmarin, Green, Pirutinsky, \& Kay, 2013). Lack of competence and confidence in including the religious or spiritual dimensions of clients lives, in both assessment and treatment, jeopardizes the effectiveness of care we are able to provide for our clients.

Research has demonstrated that integrating clients' religion/spirituality (RS) into mental health treatment can improve clinical outcomes (Koenig, King, \& Carson, 2012; Koenig, Pearce, Nelson, Shaw, Robins et al., 2015; Worthington et al., 2011). For example, clients may use RS resources to help cope with life challenges and stressors, which can also be used to help treat 
mental health disorders (Pearce, 2016). Conversely, at times, certain forms of RS may exacerbate mental health problems (Pargament, 1997; 2007). Providers need to be aware of the potential for both of these outcomes when conducting therapy.

With $78 \%$ of Americans reporting religion as somewhat or very important in their lives (Pew Research Center, 2015), religion and spirituality may be relevant in therapy for a large majority of clients. Indeed, many clients report a desire for RS issues to be integrated into their mental health treatment (Bannister, Park, Taylor, \& Bauerle, 2015; Leitz \& Hodge, 2013;

Oxhandler, Ellor, \& Stanford, in press; Post, Wade, \& Cornish, 2014; Rose et al., 2001; Stanley et al., 2011). Some clients, particularly those with higher levels of religiosity, report being concerned about how their therapists might react to their RS and prefer their therapist to have a religious affiliation (Cragun \& Friedlander, 2012; Gregory, Pomerantz, Pettibone, \& Segrist, 2008). Thus, although many clients want RS issues to be part of treatment, this does not ensure that clients will bring up RS, or that they will seek out mental health treatment in the first place, as they may be concerned about therapist bias or judgment.

Finally, clinicians are ethically mandated to demonstrate multicultural competence, of which religion and spirituality is one domain. Professional associations of psychologists, counselors, social workers, and marriage and family therapists include RS in their definitions of multiculturalism, and their guidelines require training in multicultural competence (APA, 2002; ACA, 2005; National Association of Social Workers, 2017). In addition, each profession that provides mental health treatment (e.g., psychology, social work, counseling, marriage and family therapy) requires its graduate training programs to abide by standing accreditation standards that include attention to the importance of respecting various areas of client 
diversity, including race, ethnicity, sexual orientation, gender identity, religion/spirituality, age, culture, socioeconimic status, disability, and more (APA, 2015; ACAREP, 2016; COAMFTE, 2016; CSWE, 2015). Yet, complicating matters is the fact that, to date, there is no agreed upon set of spiritual competencies, training guidelines, or methods of evaluating such competency acquisition for mental health providers (Hodge, 2018; Oxhandler \& Pargament, 2018; Vieten et al., 2016).

Clearly there are many compelling reasons for integrating religion and spirituality into treatment. However, mental health providers have tended to ignore or undervalue the role of clients' religion and spirituality in therapy (Hathaway, Scott, \& Garver, 2004). One of the main reasons for this may be that most mental health providers have little to no education or training in RS issues in clinical practice (Brawer, Handal, Fabricatore, Roberts, \& WajdaJohnston, 2002; Hage, Hopson, Siegel, Payton, \& DeFanti, 2006; Oxhandler \& Pargament, 2014; Oxhandler et al., 2015; Schafer, Handal, Brawer \& Ubinger, 2009; Schulte, Skinner, \& Calibom, 2002.) For example, only $25 \%$ of psychology (Schafer, Handal, Brawer \& Ubinger, 2009) and $30 \%$ of social work (Moffatt \& Oxhandler, 2018) training programs provide even one course in RS. Most APA-accredited psychology training programs still rely on informal and unsystematic sources of learning to train students about RS diversity (Vogel, 2013). The lack of training is not just found among psychologists and social workers, but also among those in other mental health professions. For example, marriage and family therapists and counselors have reported low levels of training and a desire for more education on RS in clinical practice (Carlson, Kirkpatrick, Hecker, \& Killmer, 2002; Oxhandler \& Parrish, 2018). Another potential reason for not including clients' RS in treatment may be tied to the fact that mental healthcare providers 
tend to have very different RS beliefs and practices than the general population, often being less religious (Oxhandler, Polson, \& Achenbaum, 2017; Shafranske \& Cummings, 2013). Currently, intrinsic religiosity is the strongest predictor of practitioners' views and behaviors regarding integrating clients' RS (Oxhandler et al., 2015; Oxhandler, 2017).

To address the gap between professional training and the needs and realities of clinical practice, we have developed an online training program to assist practitioners from varied mental health professions in building basic competence and comfort levels in integrating religion and spirituality into treatment. The competencies addressed in the training program emerged from prior empirical work on spiritual competencies in mental health (Vieten et al., 2013; Vieten et al., 2016). These researchers identified and verified 16 basic, key spiritual competencies through a comprehensive literature review, series of working groups, and surveys with experts and clinicians. They proposed these competencies as the minimum attitudes, knowledge, and skills mental health clinicians across helping professions should possess in order to be considered competent in this area (Vieten \& Scammell, 2015). To guide the development of this training program, in addition to using the work on competencies above, we also had extensive discussions with experts in the field. The result of these efforts is the online program called Spiritual Competency Training in Mental Health (SCT-MH). In this article, we will discuss how the program was developed, what it entails, who it was developed for, and future efforts to test it empirically. 


\section{Methods}

\section{Participants}

We designed this multi-disciplinary program to be relevant to mental health clinicians of all fields, including psychiatry, psychology, marriage and family therapy, clinical social work, and professional counseling, and to be appropriate for all levels of training, including graduate students, interns, and residents. Given this is a basic competency training course, clinicians who have completed an academic graduate or post-graduate course or full-day workshop in religion or spirituality may find that their competencies change less compared to those without this background.

\section{Training Delivery Method and Platform}

We chose to deliver this program online rather than in person to increase access to and convenience for a larger number of professionals. Offering the program online also allowed us to lower our costs and increase dissemination opportunities beyond the grant-funded timeline. The online platform that best met our training needs and objectives was edX, the largest nonprofit and open source provider of Massive Open Online Courses (MOOC). The edX platfrom was created in 2012 by Harvard University and MIT with the mission to "deliver high quality learning opportunities" to anyone in the world. It currently offers online courses from some of the world's top universities and institutions, and does so without cost to the participant.

In the edX online course environment, participants are provided with a well-designed, structured, yet self-paced learning opportunity. Similar to traditional learning environments, there is course content along with readings, activities, and assessments. The difference is that in the online environment, these resources, activities, and assessments are all housed in one 
location (i.e., the edX platform), which can be accessed at anytime from anywhere with an internet connection. For this training program, the edX platform was hosted by the Graduate School at the University of Maryland, Baltimore (UMB).

\section{Core Features of SCT-MH Program}

There were four core features that guided the development of the SCT-MH training program. First, the curriculum was designed to be at a basic skill level. The program aims to foster basic RS competencies with respect to the attitudes, knowledge, and skills that make for effective mental health care. The program is geared to that large majority of mental health professionals who have little, if any training, in this area, and do not necessarily intend to specialize in spiritually integrated care.

Second, SCT-MH is multidisciplinary. It focuses on core RS competencies relevant to effective mental health care in general and common to mental health disciplines and therapeutic orientations (e.g., CBT, psychodynamic, interpersonal). Attempts to target the specific interests of particular disciplines (e.g., psychiatric issues that arise in prescribing medications to RS patients or the role of religion/spiritual in marital counseling) are beyond the scope of this basic training approach.

Third, the training is grounded in state-of-the-art science and practice. It builds upon advances in knowledge gleaned from scientific studies of RS and mental health across disciplines. A variety of recent instructional materials on spiritually integrated psychotherapy and spiritual competencies were used to develop the curriculm. We also sought out input and feedback from a number of experts in the field. 
Fourth, the SCT-MH program is based on sound pedagogical principles. It makes use of proven adult-learning instructional methods, particularly within an asynchronous (prerecorded and self-paced), online platform. These include goal-setting, engaging activities, multi-modal presentations, and self-testing.

\section{Curriculum Development}

The course directors (MP and KP) created the curriculum by drawing upon instructional materials (e.g., books, papers, seminars, workshops) on spiritually integrated psychotherapy and spiritual competencies that have been disseminated over the last 15 years (e.g., Doehring, 2015; Griffith, 2010; Pargament, 2007; Pearce, 2016; Richards \& Bergin, 2005; Vieten \& Scammell, 2015). We also reached out to over 20 experts in the field for their input on the most important material that they felt should be covered in a basic competency training program. We then had five consultants and two co-investigators ( $\mathrm{HO}$ and $\mathrm{CV}$ ) provide detailed feedback on all of the material in the eight modules. This feedback was used to revise the curriculum. The content was then given to our instructional design team who provided further edits. The design team helped to present the content in a way that enhanced learning and retention and that captured the audience's attention and interest. For example, written case studies were turned into video clips demonstrating the case with visual and auditory features.

The curriculum was designed using best practices in education. This included developing and using learning objectives to drive the choice of content and activities in each of the modules (rather than letting content drive learning objectives). We also chose activities based on adult learning principles (Taylor \& Parsons, 2011). These include ample opportunities for engagement with material (e.g., self-reflection questions with text boxes for responses, self 
knowledge checks), using short videos rather than lengthy PowerPoints to enhance connection and interest, and providing a variety of activities and examples to reinforce major concepts and to show how these concepts can be applied in clinical settings.

Each of the eight modules can be completed in approximately 45-60 minutes. We chose a total of six to eight hours of training time because this roughly correlates to a day's worth of in-person training. We believe this is sufficient time to achieve basic competency in this area. We also hope that the program whets providers' appetite for further advanced training. To enhance motivation to complete the training program, participants will have the opportunity to earn CE or CME credits upon completion.

\section{Results}

\section{Structure of the Modules}

Each of the eight modules begins with a brief video introduction in which one of the course directors provides an outline of the module. This is followed by a list of the module's objectives and an overview of the activities that will be presented in the module. Most of the modules consist of three sections of content. Each section consists of a combination of materials, including text on the screen, video presentations, case studies (text and video), and audio recordings. Each module also includes a self-reflection question with a textbox in which participants can type their response, as well as several knowledge check questions at the end of the module to assess their comprehension of the material. At the end of the program, we provide a comphrehensive list of other resources for those interested in learning more about this topic. 
The training program was designed to develop basic competency in 16 empiricallyderived spiritual competencies for mental health (Vieten et al., 2013). The 16 competencies fall into one of three categories: attitudes, knowledge, or skills. In Table 1, we provide a list of the competencies that the content of the program was designed to develop (See Table 1).

\section{Description of the Training Modules}

The following is a brief description of the topics covered in each of the eight training modules. Table 2 provides information on what competencies were addressed in each module (See Table 2).

Module 1: Introduction and Orientation. In the first module, participants are oriented to the goals and learning objectives of the training program to build motivation and set realistic expectations. Clear instructions are provided on how to use the edX software, effectively engage with the material, and complete learning activities and assessments. We define spiritually integrated mental health care and outline empirically-based rationales for providing spiritually integrated care. Participants then learn what is and is not required to provide spiritually integrated care. Finally, challenges to this type of care are introduced, including emotional-sensitivity, ethical issues, and personal values and biases. As with all modules, this module includes a self-reflection question related to one of the module's topics and concludes with several multiple choice knowledge check questions.

Module 2: Understanding Spirituality. In Module 2, religion and spirituality are defined and common stereotypes and misconceptions are challenged. National survey results on Americans' spiritual identification and analysis of future trends are reviewed, including the rise of the "nones." The varieties of religion and spirituality are introduced (e.g., values, beliefs, 
practices, experiences, relationships, and motivations) and a brief comparison is provided of world religions, atheism, cults, spiritual/not religious, and cafeteria-style religion. The module concludes with a discussion of the ways spirituality develops over the lifespan and the forces that influence this process: biological, psychodynamic, sociocultural, and theological.

\section{Module 3: Guiding Principles for Spiritually Integrated Mental Health Care. In this}

module, participants learn how therapists' RS competencies and biases influence treatment and patient outcomes. Spirituality in the therapeutic relationship is reviewed, including issues with clients who share the same religious tradition as the therapist, come from a very different religious tradition than the therapist, are very religious, are atheist/agnostic, or are religiously victimized. Finally, participants learn about the dangers of spiritual rejectionism or proselytizing in therapy, and why respecting spiritual diversity is critical for effective and ethical care.

Module 4: Distinguishing between Helpful and Harmful Types of Spirituality. In Module 4, participants learn how to discern ways that religion or spirituality can be part of the solution or part of the problem in mental health treatment. Life-affirming forms of spirituality are defined and examples of spiritual resources provided. This is followed by a discussion of lifelimiting forms of spirituality and examples of spiritual problems and struggles. The complex interplay between religion, spirituality, and mental health problems is reviewed. Participants learn how spirituality can both shape and be shaped by mental health problems. Issues related to diagnosing religious and spiritual problems using the DSM-V criteria are discussed. Finally, tools for distinguishing spiritual experiences from psychopathology are provided.

Module 5: Assessing Spirituality in Mental Health Care. This module focuses on the assessment of spirituality as a multi-step process, which can be interwoven into the larger 
process of treatment. Participants learn spiritual dialogue skills to form an effective therapeutic alliance. A discussion follows on the importance of placing clients within their larger social, cultural, and religious context when conducting a spiritual assessment and planning spiritually integrated care. Definitions of and distinctions between initial, implicit, and explicit spiritual assessment are provided. The module concludes with information about formal spiritual assessments, including the use of quantitative measures, spiritual screening, and structured interviews.

Module 6: Mobilizing Spiritual Resources. This module focuses on concrete ways that therapists can help clients access their spiritual resources. First, therapists learn general guidelines for integrating spiritual resources into therapy. Then, a discussion follows on how therapists can cultivate and mobilize spiritual resources in therapy. This discussion draws upon the growing body of empirical literature on spiritually integrated therapies. Illustrations are provided demonstrating how therapists can use these mobilization skills in clinical practice.

Module 7: Addressing Spiritual Problems. In this module, participants learn about spiritual problems and struggles, as well as a rationale and tools for assessing spiritual problems in therapy. Various types of spiritual problems are addressed, including intrapsychic spiritual conflict, interpersonal spiritual conflict, supernatural conflict, spiritual extremism, and spiritual rigidity. Therapists are given resources and tools to effectively address spiritual problems in therapy. Emphasis is placed on helping therapists understand their limits and the resources that are available to them through consultation, supervision, collaboration with clergy, and referral.

Module 8: Putting it All Together, Challenges, and Future Directions. In the final module, participants learn about the ethical challenges of spiritually integrated mental health 
care. Next, several cutting-edge approaches to spiritually integrated care are discussed. Then, participants have the opportunity to synthesize and apply their knowledge from all eight modules to a hypothetical clinical case study by engaging in analysis, assessment, and treatment planning decision making. The module concludes with suggested next steps for participants interested in furthering their competencies in spiritually integrated mental health care.

\section{Discussion}

In the next phase of this project, the SCT-MH program will be empirically tested to examine to what extent it is a feasible, helpful, and effective way to share knowledge and increase competencies in spirituality and mental health care among mental health care providers from diverse professions. To do so, we will assess pre-post changes among program participants with respect to their basic spiritual competencies (attitudes, knowledge, and skills) in mental health care. We predict that participating in this program will lead to improvements in providers' attitudes, knowledge, and skills as they relate to spirituality and mental health. We will also evaluate participants' levels of program satisfaction and gather their concrete suggestions for ways to improve the training program. This quantitative and qualitative data will be used to refine the program.

As far as we know, this empirically-driven, online training is the first of its kind. The program has a number of strengths. The content was derived from numerous peer-reviewed publications with input from leading experts in the field of spirituality and mental health. It is designed to be multidisciplinary, allowing mental health providers from any discipline and therapeutic orientation to participate. The material is applicable for working with clients from 
diverse religious and spiritual traditions. Finally, the online format, with its ease of access and relatively low expense, has the potential to reach a large audience of mental health professionals who are interested in training in this area with the flexibility and convenience to complete the 6-8 hours of training from wherever the participant has internet access. The program is limited in that it offers only a basic level of training and results on its effectiveness are still forthcoming.

Conclusion. Our long-term plan is to disseminate the program widely, providing access to licensed providers and trainees ${ }^{1}$. Our hope is that this program helps to reduce the gap between standard graduate and post-graduate training and the realities of clinical practice. In doing so, we hope to better equip providers to address this relatively neglected but vital area of clinical work and contribute to the continued improvement of mental health care.

\footnotetext{
${ }^{1}$ If you or your colleagues are interested in participating in the SCT-MH program, please contact the first author at michelle.pearce@umaryland.edu
} 
Table 1. (Adapted from Vieten et al., 2016)

Spiritual and Religious Competencies for Mental Health Professionals

\section{Attitudes}

1) Mental health professionals demonstrate empathy, respect, and appreciation for clients from diverse spiritual, religious, or secular backgrounds and affiliations.

2) Mental health professionals view spirituality and religion as important aspects of human diversity, along with factors such as race, ethnicity, sexual orientation, socioeconomic status, disability, gender, and age.

3) Mental health professionals are aware of how their own spiritual and/or religious background and beliefs may influence their clinical practice, and their attitudes, perceptions, and assumptions about the nature of psychological processes.

\section{Knowledge}

4) Mental health professionals know that many diverse forms of spirituality and/or religion exist, and explore spiritual and/or religious beliefs, communities, and practices that are important to their clients.

5) Mental health professionals can describe how spirituality and religion can be viewed as overlapping, yet distinct, constructs.

6) Mental health professionals understand that clients may have experiences that are consistent with their spirituality or religion, yet may be difficult to differentiate from psychopathological symptoms. 
7) Mental health professionals recognize that spiritual and/or religious beliefs, practices and experiences develop and change over the lifespan.

8) Mental health professionals are aware of internal and external spiritual and/or religious resources and practices that research indicates may support psychological well-being, and recovery from psychological disorders.

9) Mental health professionals can identify spiritual and religious experiences, practices and beliefs that may have the potential to negatively impact psychological health.

10) Mental health professionals can identify legal and ethical issues related to spirituality and/or religion that may surface when working with clients.

\section{Skills}

11) Mental health professionals are able to conduct empathic and effective psychotherapy with clients from diverse spiritual and/or religious backgrounds, affiliations, and levels of involvement.

12) Mental health professionals inquire about spiritual and/or religious background, experience, practices, attitudes and beliefs as a standard part of understanding a client's history.

13) Mental health professionals help clients explore and access their spiritual and/or religious strengths and resources.

14) Mental health professionals can identify and address spiritual and/or religious problems in clinical practice, and make referrals when necessary.

15) Mental health professionals stay abreast of research and professional developments 
regarding spirituality and religion specifically related to clinical practice, and engage in ongoing assessment of their own spiritual and religious competency.

16) Mental health professionals recognize the limits of their qualifications and competence in the spiritual and/or religious domains, including their responses to clients spirituality and/or religion that may interfere with clinical practice, so that they a) seek consultation from and collaborate with other qualified clinicians or spiritual/religious sources (e.g. priests, pastors, rabbis, imam, spiritual teachers), b) seek further training and education, and/or c) refer appropriate clients to more qualified individuals and resources. 
Table 2.

Training Program Modules and Spiritual Competencies.

\begin{tabular}{|c|c|}
\hline Training Program Module & Spiritual Competencies Addressed in Module \\
\hline \multirow[t]{3}{*}{ Module 1: Introduction and Orientation } & \#3. Being aware of your own beliefs: Attitude \\
\hline & $\begin{array}{l}\text { \#10. Being aware of legal and ethical issues: } \\
\text { Knowledge }\end{array}$ \\
\hline & \#15. Staying up-to-date: Skill \\
\hline \multirow[t]{3}{*}{ Module 2: Understanding Spirituality } & $\begin{array}{l}\text { \#5. Understanding spirituality and religion as } \\
\text { different but overlapping: Knowledge }\end{array}$ \\
\hline & $\begin{array}{l}\text { \#7. Recognizing spiritual development over } \\
\text { the lifespan: Knowledge }\end{array}$ \\
\hline & $\begin{array}{l}\text { \#8. Learn about diverse beliefs and practices: } \\
\text { Knowledge }\end{array}$ \\
\hline \multirow[t]{3}{*}{$\begin{array}{l}\text { Module 3: Guiding Principles for Spiritually } \\
\text { Integrated Mental Health Care }\end{array}$} & $\begin{array}{l}\text { \#1. Demonstrating empathy, respect, and } \\
\text { appreciation: Attitude }\end{array}$ \\
\hline & $\begin{array}{l}\text { \#2. Appreciating religious and spiritual } \\
\text { diversity: Attitude }\end{array}$ \\
\hline & \#3. Being aware of your own beliefs: Attitude \\
\hline \multirow[t]{3}{*}{$\begin{array}{l}\text { Module 4: Distinguishing between Helpful and } \\
\text { Harmful Types of Spirituality }\end{array}$} & $\begin{array}{l}\text { \#6. Know the difference between spirituality } \\
\text { and psychopathology: Knowledge }\end{array}$ \\
\hline & $\begin{array}{l}\text { \#8. Learn about clients' spiritual and religious } \\
\text { resources: Knowledge }\end{array}$ \\
\hline & $\begin{array}{l}\text { \#9. Recognize harmful religious and spiritual } \\
\text { involvement: Knowledge }\end{array}$ \\
\hline \multirow[t]{2}{*}{$\begin{array}{l}\text { Module 5: Assessing Spirituality in Mental } \\
\text { Health Care }\end{array}$} & $\begin{array}{l}\text { \#11. Working with religious and spiritual } \\
\text { diversity: Skill }\end{array}$ \\
\hline & $\begin{array}{l}\text { \#12. Conducting a religious and spiritual } \\
\text { assessment: Skill }\end{array}$ \\
\hline \multirow[t]{2}{*}{$\begin{array}{l}\text { Module 6: Assessing and Mobilizing Spiritual } \\
\text { Resources }\end{array}$} & $\begin{array}{l}\text { \#8. Learn about clients' spiritual and religious } \\
\text { resources: Knowledge }\end{array}$ \\
\hline & $\begin{array}{l}\text { \#13. Helping clients identify and access their } \\
\text { religious and spiritual resources: Skill }\end{array}$ \\
\hline \multirow[t]{3}{*}{$\begin{array}{l}\text { Module 7: Assessing and Addressing Spiritual } \\
\text { Problems }\end{array}$} & $\begin{array}{l}\text { \#9. Recognize harmful religious and spiritual } \\
\text { involvement: Knowledge }\end{array}$ \\
\hline & $\begin{array}{l}\text { \#14. Helping clients identify and deal with } \\
\text { spiritual and religious problems: Skill }\end{array}$ \\
\hline & \#16. Acknowledging your limits: Skill \\
\hline $\begin{array}{l}\text { Module 8: Putting it All Together, Challenges, } \\
\text { and Future Directions }\end{array}$ & $\begin{array}{l}\text { \#10. Develop awareness of legal and ethical } \\
\text { issues: Knowledge }\end{array}$ \\
\hline
\end{tabular}


\#15. Staying up-to-date: Skill

\#16. Acknowledging your limits: Skill

\#1-16 Summary and application of all 16 competencies 


\section{References}

American Counseling Assocation (2005). Code of ethics and standards of practice. Alexandria, VA: American Counseling Association.

American Psychological Association (2002). Ethical principles of psychologists and code of conduct. American Psychologist, 57, 1060-1073.

American Psychological Association (2015). Commission on accreditation: Implementing regulations related to the standards of accreditation. Retrieved from: http://www.apa.org/ed/accreditation/section-c-soa.pdf

Bannister, S. H., Park, H. S., Taylor, S., \& Bauerle (2015). Clients' expectations and preferences for marital Christian counseling: A chronological literature review and contemporary evaluation. Social Work \& Christianity, 42, 63-95.

Brawer, P. A., Handal, P. J., Fabricatore, A. N., Roberts, R., \& Wajda-Johnston, V. A. (2002). Training and education in religion/spirituality within APA-accredited clinical psychology programs. Professional Psychology: Research and Practice, 33(2), 203-206.

Carlson T. D., Kirkpatrick D., Hecker L., \& Killmer M. (2002). Religion, spirituality, and marriage and family therapy: A study of family therapists' beliefs about the appropriateness of addressing religious and spiritual issues in therapy. The American Journal of Family Therapy, 30(2), 157-171. http://dx.doi.org/10.1080/019261802753573867

Commission on Accreditation for Marriage and Family Therapy Education (2016). Accreditation standards: Graduate \& post-graduate marriage and family therapy training programs. Retrieved from: 
https://www.coamfte.org/Documents/COAMFTE/Version\%2012/COAMFTE_Accreditati on_Standards_Version_12.pdf

Council for Accreditation of Counseling and Related Educational Programs. (2015). 2016 CACREP standards. Retrieved from http://www.cacrep.org/wpcontent/uploads/2018/05/2016-Standards-with-Glossary-5.3.2018.pdf

Council on Social Work Education. (2015). Educational policy and accreditation standards for baccalaureate and master's social work programs. Retrieved from http://www.cswe.org.

Cragun, C. L. \& Friedlander, M. L. (2012). Experiences of Christian clients in secular psychotherapy: A mixed methods investigation. Journal of Counseling Psychology, 59, 379-391. doi: 10.1037/a0028283.

Dillman, D. A., Smyth, J. D., and Christian, L. M. (2015). Internet, mail, phone, and mixed-mode surveys: The tailored design method ( $4^{\text {th }}$ ed.). Hoboken, NJ: Wiley.

Doehring, C. (2015). The practice of pastoral care, revised and expanded edition. Louisville, KY: Westminster John Knox Press.

Gregory, C., Pomerantz, A. M., Pettibone, J. C., \& Segrist, D. J. (2008). The effect of psychologists' disclosure of personal religious background on prospective clients. Mental Health, Religion, and Culture, 11, 369-373. doi: 10.1080/13674670701438739.

Griffith, J. L. (2010). Religion that heals, religion that harms: A guide for clinical practice. New York: Guilford Press.

Hage, S. M., Hopson, A., Siegel, M., Payton, G., \& DeFanti, E. (2006). Multicultural training in spirituality: An interdisciplinary review. Counseling and Values, 50, 217-234. 
Hathaway, W. L., Scott, S. Y., \& Garver, S. A. (2004). Assessing religious/spiritual functioning: A neglected domain in clinical practice? Professional Psychology: Research and Practice, 35, 97-104.

Hodge, D. (2018). Spiritual competence: What is it, why is it necessary, and how to develop it. Journal of Ethnic and Cultural Diversity in Social Work, 27, 124-139.

Koenig, H. G., King, D. E., \& Carson, V. B. (2012). Handbook of religion and health (2 ${ }^{\text {nd }}$ ed.). New York: Oxford University Press.

Koenig, H.G., Pearce, M.J., Nelson, B., Shaw, S.F., Robins, C.J., Daher, N., Cohen, H.J., Berk, L.S., Belinger, D., Pargament, K.I., Rosmarin, D.H., Vasegh, S., Kristeller, J., Juthani, N., Nies, D. \& King, M.B. (2015). Religious vs. conventional cognitive-behavioral therapy for major depression in persons with chronic medical illness: A pilot randomized trial. Journal of Nervous and Mental Disease, 203(4), 243-251.

Leitz, C. A. \& Hodge, D. R. (2013). Incorporating spirituality into substance abuse counseling: Examining the perspectives of service recipients and providers. Journal of Social Service Research, 39, 498-510. doi: 10.1080/01488376.2012.676023.

Moffatt, K. \& Oxhandler, H. K. (In press). Religion and spirituality in master of social work education: Past, present, and future considerations. Journal of Social Work Education. National Association of Social Workers. (2017). Code of ethics. Retrieved from https://www.socialworkers.org/LinkClick.aspx?fileticket=ms ArtLqzel\%3d\&portalid Oxhandler, H. K. (2017). Namaste theory: A quantitative grounded theory on religion and spirituality in mental health treatment. Religions, 8(9), 168. doi:10.3390/rel8090168 Oxhandler, H. K., Ellor, J. W., \& Stanford, M. S. (In press). Client preferences for integrating 
religion/spirituality in mental health treatment: Scale development and client responses. Social Work.

Oxhandler, H. K. \& Pargament, K. I. (2018). Measuring religious and spiritual competence across helping professions: Previous efforts and future directions. Spirituality in Clinical Practice, 5(2), 120-132. doi: 10.1037/scp0000149

Oxhandler, H. K. \& Parrish, D. E. (2016). The development and validation of the Religious/Spiritually Integrated Practice Assessment Scale. Research on Social Work Practice, 26, 295-307. doi: 10.1177/1049731514550207.

Oxhandler, H. K. \& Parrish, D. E. (2018). Integrating clients' religion/spirituality in clinical practice: A comparison among social workers, psychologists, counselors, marriage and family therapists, and nurses. Journal of Clinical Psychology, 74, 680-694.

Oxhandler, H. K., \& Pargament, K. I. (2014). Social work practitioners' integration of clients' religion and spirituality in practice: A literature review. Social Work, swu018.

Oxhandler, H. K., Parrish, D. E., Torres, L. R., \& Achenbaum, W. A. (2015). The integration of clients' religion/spirituality in social work practice: A national survey. Social Work, 60, 228-237. doi: 10.1093/sw/swv018.

Oxhandler, H. K., Polson, C., \& Achenbaum, W. A. (2018). The religiosity and spiritual beliefs and practices of clinical social workers: A national survey. Social Work 63(1), 47-56. doi: $10.1093 / \mathrm{sw} / \mathrm{sw} \times 055$

Pargament, K. I. (1997). The psychology of religion and coping: Theory, research, practice. New York: Guilford Press. 
Pargament, K. I. (2007). Spiritually integrated psychotherapy: Understanding and addressing the sacred. New York: Guilford Press.

Pearce, M. (2016). Cognitive behavioral therapy for Christians with depression: A practical toolbased primer. West Conshohocken, PA: Templeton Press.

Pew Research Center. (2015, May) U.S. religious landscape study. Retrieved from: http://www.pewforum.org/religious-landscape-study/

Post, B. C., Wade, N. G., \& Cornish, M. A. (2014). Religion and spirituality in group counseling: Beliefs and preferences of university counseling center clients. Group Dynamics: Theory, Research, and Practice, 18, 53-68. doi:10.1037/a0034759

Richards, P. S., \& Bergin, A. E. (2005). A spiritual strategy for counseling and psychotherapy (2 ${ }^{\text {nd }}$ ed.). Washington DC: American Psychological Association.

Rose, E. M., Westefeld, J. S., \& Ansley, T. N. (2001). Spiritual issues in counseling: Clients' beliefs and preferences. Journal of Counseling Psychology, 48, 61-71. doi:10.1037/00220167.48.1.61

Rosmarin, D., Green, D., Pirutinsky, S., \& Kay, D. (2013). Attitudes toward spirituality/religion among members of the Association for Behavioral and Cognitive Therapies. Professional Psychology: Research and Practice, 44, 424-433.

Schulte, D. L., Skinner, T. A., \& Calibom, C. D. (2002). Religious and spiritual issues in counseling psychology training. The Counseling Psychologist, 30(1) 118-134.

Shafranske, E. P. \& Cummings, J. P. (2013). Religious and spiritual beliefs, affili- ations, and practices of psychologists. In K. I. Pargament, A. Mahoney, E. P. Shafranske, K. I. Pargament, A. Mahoney, E. P. Shafranske (Eds.), APA handbook of psychology, religion, 
and spirituality (Vol 2): An applied psychology of religion and spirituality (pp. 23-41). Washington, DC: American Psychological As- sociation. doi:10.1037/14046-002

Stanley, M. A., Bush, A. L., Camp, M. E., Jameson, J. P., Philips, L. L., Barber, C. R., Cully, J. A. (2011). Older adults' preferences for religion/spirituality in treatment for anxiety and depression. Aging and Mental Health, 15, 334-343. doi:10.1080/13607863.2010.519326

Taylor, L. \& Parsons, J. (2011). Improving Student Engagement. Current Issues in Education, 14(1), 1-33. Retrieved from https://www.google.com/url?sa=t\&rct=j\&q=\&esrc=s\&source=web\&cd=4\&ved=0ahUKE wjRnszLibAhXvzVkKHVILBVcQFghLMAM\&url=https\%3A\%2F\%2Fcie.asu.edu\%2Fojs\%2Fin dex.php\%2Fcieatasu\%2Farticle\%2Fdownload\%2F745\%2F162\%2F0\&usg=AOvVaw1KNI a $\underline{\text { KXpORn2LRXW3OOBu }}$

Vieten, C., \& Scammell, S. (2015). Spiritual and religious competencies in clinical practice: Guidelines for psychotherapists and mental health professionals. Oakland, CA: New Harbinger Publications.

Vieten, C., Scammell, S., Pierce, A., Pilato, R., Ammondson, I., Pargament, K. I., \& Lukoff, D. (2016). Competencies for psychologists in the domains of religion and spirituality. Spirituality in Clinical Practice, 3(2), 92.

Vieten, C., Scammell, S., Pilato, R., Ammondson, I., Pargament, K. I., \& Lukoff, D. (2013). Spiritual and religious competencies for psychologists. Psychology of Religion and Spirituality, 5(3), 129. 
Vogel, M. J. (2013). Examining religion and spirituality as diversity training: A multidimensional study of training in the American Psychological Association. Doctoral Dissertation, George Fox University, Newberg. (3515671)

Worthington, E.L., Hook, J.N., Davis, D.E., \& McDaniel, M.A. (2011). Religion and spirituality. Journal of Clinical Psychology: In Session, 67(2), 204-214. 